\title{
DIMENSI PARTISI DARI GRAF LOLIPOP DAN GRAF JAHANGIR DIPERUMUM
}

\author{
MEIZA FIQRUL HANIF, DES WELYYANTI, EFENDI \\ Program Studi S1 Matematika, \\ Fakultas Matematika dan Ilmu Pengetahuan Alam, Universitas Andalas, \\ Kampus UNAND Limau Manis Padang, Indonesia, \\ email: Meiza.hanifr7@yahoo.com
}

\begin{abstract}
Abstrak. Dimensi partisi adalah pengelompokan semua titik di $G$ ke dalam sejumlah kelas partisi dan menentukan jarak setiap titik terhadap setiap kelas partisi tersebut [7]. Representasi dari $v \in V(G)$ terhadap himpunan $\Pi$ dari $k$-vektor dapat ditulis dalam bentuk $\left(d\left(v, S_{1}\right), d\left(v, S_{2}\right), \cdots, d\left(v, S_{k}\right)\right)$. Partisi terurut $\Pi$ pada himpunan titik pada graf $G$ merupakan partisi penyelesaian diselesaikan jika representasi titik berbeda. Minimum dari $k$ sedemikian sehingga terdapat $k$-partisi $\Pi$ pada graf $G$ dinamakan partisi dimensi dari $G$, dinotasikan sebagai $p d(G)$. Dalam makalah ini, akan dibahas tentang cara penentuan dimensi partisi dari sebuah graf Lolipop dan sebuah graf Jahangir diperumum.
\end{abstract}

Kata Kunci: Representasi, Dimensi partisi, Graf Lolipop, Graf Jahangir Diperumum

$\begin{array}{lll}\text { Diterima } & : & \text { 26 Juli } 2018 \\ \text { Direvisi } & : & 17 \text { September } 2018 \\ \text { Dipublikasikan } & : & 21 \text { Desember 2018 }\end{array}$

\section{Pendahuluan}

Teori graf merupakan pokok bahasan salah satu ilmu matematika yang banyak mendapat perhatian karena model-modelnya sangat berguna untuk aplikasi yang luas, diantaranya diterapkan dalam jaringan komunikasi, transportasi, ilmu komputer, riset operasi, dan rancangan suatu bangunan. Banyak sekali penelitian terbaru tentang graf, mulai dari jenis-jenis graf, dimensi partisi, pewarnaan lokasi, dan lain-lain.

Graf $G=(V, E)$ adalah pasangan himpunan titik $V(E)$ dan himpunan sisi $E(G)$. Pengaitan titik-titik pada graf membentuk sisi dan dapat direpresentasikan pada gambar sehingga membentuk pola graf tertentu. Pola-pola yang terbentuk pada graf dikelompokkan menjadi kelas-kelas graf.

Konsep dimensi partisi untuk graf terhubung pertama kali diperkenalkan oleh Chartrand, dkk [1]. Untuk suatu titik $v$ dari graf terhubung $G$ dan suatu himpunan $S \subseteq V(G)$, jarak antara $v$ dan $S$ didefinisikan sebagai $d(v, S)=\min \{d(v, x) \mid x \in S\}$. Untuk $k$-partisi $\Pi=\left\{S_{1}, S_{2}, \cdots, S_{k}\right\}$ dari $V(G)$, representasi dari $v$ terhadap $\Pi$ didefinisikan sebagai $r(v \mid \Pi)=\left(d\left(v, S_{1}\right), d\left(v, S_{2}\right), \cdots, d\left(v, S_{k}\right)\right)$. Jika untuk setiap $u$ dan $v$ di $V(G)$ berlaku $r(u \mid \Pi) \neq r(v \mid \Pi)$, maka partisi $\Pi$ adalah partisi partisi penyelesaian. Banyak elemen atau anggota suatu himpunan disebut kardinalitas. Kardinalitas minimum dari partisi penyelesaian disebut dimensi partisi dari $G$.

Banyak peneliti telah melakukan penelitian dalam menentukan dimensi partisi 
untuk spesifik kelompok graf. Tomescu [4] pada tahun 2007 menemukan dimensi partisi dari sebuah graf roda. Pada makalah ini, akan ditentukan partisi dimensi dari sebuah graf Lolipop dan sebuah graf Jahangir diperumum.

\section{Terminologi Graf}

Graf $G$ adalah pasangan himpunan terurut, dinotasikan dengan $G=(V, E)$, yang dalam hal ini $V$ adalah himpunan titik tak kosong dari obyek-obyek yang disebut sebagai titik dan $E$ adalah himpunan sisi-sisi yang menghubungkan dua titik di graf $\mathrm{G}$ tersebut. Himpunan titik-titik pada graf $G$ dinotasikan dengan $V(G)$ dan himpunan sisi-sisinya dinotasikan dengan $E(G)$.

Lintasan yang panjangnya $n$ dari titik awal $v_{0}$ ke titik tujuan $v_{n}$ pada graf $G$ adalah barisan berselang-seling titik-titik dan sisi-sisi yang berbentuk $v_{0}, e_{1}, v_{1}, e_{2}, v_{2}, \cdots, v_{n+1}, e_{n}, v_{n}$ sedemikian sehingga $e_{1}=\left(v_{0}, v_{1}\right), e_{2}=$ $\left(v_{1}, v_{2}\right), \cdots, e_{n}=\left(v_{n-1}, v_{n}\right)$ adalah sisi dari graf $G$. Panjang lintasan adalah banyaknya sisi yang terdapat pada lintasan tersebut. Jarak dari $u$ ke $v$, dinotasikan dengan $d(u, v)$ adalah panjang dari lintasan terpendek dari $u$ ke $v$.

Graf lintasan adalah suatu graf sederhana yang terdiri dari satu lintasan. Graf lintasan dengan $n$ titik yang dilambangkan dengan $P_{n}$, graf lintasan dengan $n$ titik memiliki $n-1$ sisi. Pada Gambar 1 diperlihatkan graf lintasan dengan 4 dan 5 titik.

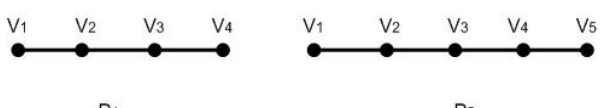

P5

Gambar 1. Graf Lintasan $P_{4}$ dan $P_{5}$

Suatu graf $G$ dikatakan graf terhubung jika untuk setiap pasang titik $u, v \in$ $V(G)$ dengan $G$ suatu graf sederhana, terdapat suatu lintasan yang menghubungkan $u$ dan $v$. Graf Lengkap adalah suatu graf yang setiap titiknya saling bertetangga. Graf lengkap dengan $n$ buah simpul dilambangkan dengan $K_{n}$. Graf Lingkaran(cycle) dilambangkan dengan $C_{n}$ dengan $n \geq 3$, adalah sebuah graf yang setiap titiknya berderajat dua. Banyak titik $C_{n}$ sama dengan banyak sisi $C_{n}$, yaitu $n$. Graf Roda (wheels) adalah graf lingkaran yang setiap titiknya dihubungkan dengan satu titik ditengah lingkaran, dinotasikan dengan $W_{n}$ untuk $n \geq 3$. Jika $e$ adalah sisi dari graf $G$, maka $G-e$ adalah subgraf dari $G$ yang memiliki himpunan titik yang sama seperti $G$ dan semua sisi dari $G$ kecuali $e$. suatu sisi dalam graf terhubung $G$ disebut Jembatan (bridge), jika $G-e$ tidak terhubung.

\subsection{Graf Lolipop dan Graf Jahangir Diperumum}

Weisstein [6] mendefinisikan graf lolipop sebagai suatu graf yang diperoleh dengan menggabungkan sebuah graf lengkap $K_{m}$ pada sebuah lintasan $P_{n}$ melalui sebuah jembatan. Penggabungan graf lengkap $K_{m}$ dengan graf lintasan $P_{n}$ dihubungkan di titik $m$ pada $K_{m}$. Graf lolipop dapat dinotasikan dengan $L_{m, n}$ dimana $m$ meny- 
atakan banyaknya titik pada graf lengkap $K_{m}$ dan $n$ merupakan banyaknya titik pada graf lintasan $P_{n}$. Pada Gambar 2 diberikan gambar graf lolipop.

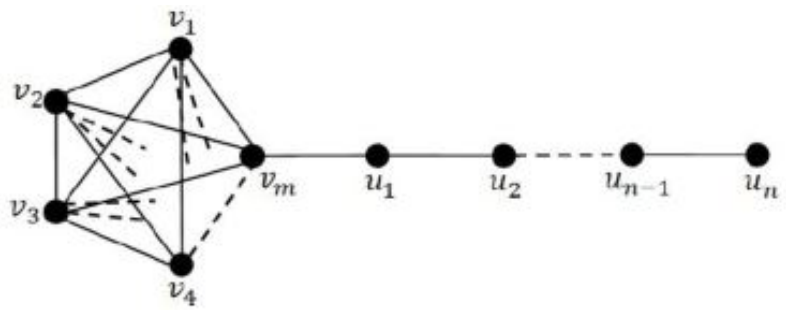

Gambar 2. Graf $L_{m, n}$

Mojdeh dan Ghameshlou [3] mendefinisikan graf Jahangir diperumum yang dinotasikan $J_{m, n}$ dengan $n \geq 3$ adalah suatu graf dengan $n m+1$ titik yang memuat sebuah siklus $C_{m n}$ yang mana $m n$ adalah sebuah perkalian antara $m$ dan $n$, dan satu titik tambahan yang bertetangga dengan $n$ titik dari $C_{m n}$, dan masing-masing dari $n$ titik tersebut memiliki jarak $m$ satu sama lainnya. Misalkan $V\left(J_{m, n}\right)=V\left(C_{m n}\right) \cup\left\{u_{1}\right\}$ atau $V\left(J_{m, n}\right)=V\left(P_{m}\right) \cup V\left(W_{n}\right)$ dimana $V\left(P_{m}\right)=\left\{v_{1}, v_{2}, \cdots, v_{n(m-1)}\right\}$ dan $V\left(W_{n}\right)=\left\{u_{1}, u_{2}, \cdots, u_{n+1}\right\}$, diperoleh $V\left(J_{m, n}\right)=\left\{u_{1}, u_{2}, \cdots, u_{n+1}, v_{1}, v_{2}, \cdots, v_{n(m-1)}\right\}$. Pada Gambar 3 diberikan gambar graf Jahangir diperumum.

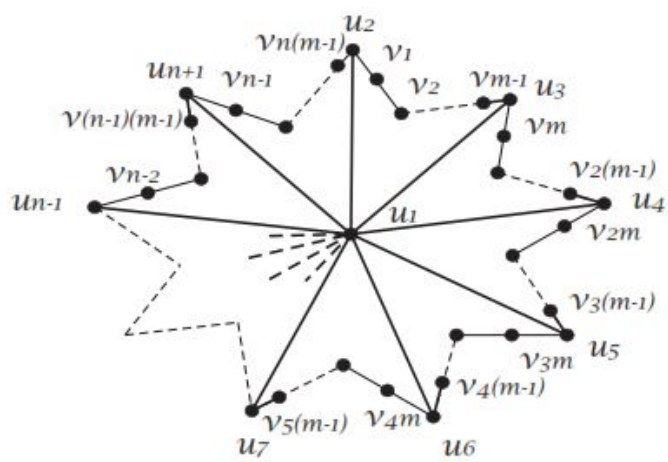

Gambar 3. Graf $J_{m, n}$

\subsection{Dimensi Partisi}

Dimensi partisi dari sebuah graf $\mathrm{G}$ dikenalkan oleh Chartrand, dkk [1]. Mereka mengelompokkan semua titik di $G$ ke dalam sejumlah kelas partisi dan menentukan jarak setiap titik terhadap setiap kelas partisi tersebut.Misalkan $\Pi=\left\{S_{1}, S_{2}, \cdots, S_{k}\right\}$ merupakan partisi terurut dari $V(G)$ dan $v \in V(G)$. Representasi titik $v \in V(G)$ terhadap himpunan $\Pi$ dari $k$-vektor, dinotasikan dengan $r(v \mid \Pi)$ dapat ditulis dalam 
bentuk $\left(d\left(v, S_{1}\right) d\left(v, S_{2}\right), \cdots, d\left(v, S_{k}\right)\right)$. Jika titik-titik yang berbeda di $G$ mempunyai representasi yang berbeda terhadap $\Pi$, maka $\Pi$ disebut partisi penyelesaian. Jika untuk 2 buah titik yang berbeda terdapat $u, v \in V(G)$ berlaku $r(u \mid \Pi) \neq r(v \mid \Pi)$, maka $\Pi$ disebut partisi pembeda dari $V(G)$. Banyak elemen atau anggota suatu himpunan disebut kardinalitas. Kardinalitas dari partisi penyelesaian minimum disebut dimensi partisi dari $G$. Dimensi partisi dari graf $G$ dinotasikan dengan $\operatorname{pd}(G)$.

Teorema 2.1. [7] Misalkan $G$ suatu graf terhubung dengan orde $n \geq 2$. Maka $p d(G)=2$ jika dan hanya jika $G=P_{n}$.

Lema 2.2. [7] Misalkan $\Pi$ suatu partisi pembeda pada $V(G)$ dengan $u, v \in V(G)$. Jika $d(u, w)=d(v, w)$ untuk setiap titik $w \in V(G)-\{u, v\}$, maka $u$ dan $v$ termuat pada kelas partisi yang berbeda pada $\Pi$.

\section{Dimensi Partisi Graf Lolipop}

Pada bab ini akan dibahas mengenai dimensi partisi dari graf lolipop yaitu, menggabungkan sebuah graf lengkap $K_{m}$ pada sebuah graf lintasan $P_{n}$ melalui sebuah jembatan.

Teorema 3.1. Misalkan $L_{m, n}$ graf lolipop dengan $m \geq 3$ dan $n \geq 1$ maka $p d\left(L_{m, n}\right)=m$.

Bukti. Misalkan $L_{m, n}$ adalah graf Lolipop untuk $m \geq 3$ dan $n \geq 1$ dengan himpunan titik $V\left(L_{m, n}\right)$. Pandang dua kasus berikut.

Kasus 1. Untuk $m=3$ dan $n=1$.

Akan ditunjukkkan $p d\left(L_{3,1}\right)=3$, Yaitu dengan menunjukkan bahwa

(i) $p d\left(L_{3,1}\right) \geq 3$, Berdasarkan Teorema 2.1 dan $K_{3}$ adalah subgraf dari $L_{3,1}$.

(ii) $p d\left(L_{3,1}\right) \leq 3$, Yaitu dengan menunjukkan bahwa himpunan titik $L_{3,1}$ dibagi menjadi 3 partisi, sedemikian sehingga representasi setiap titik berbeda, maka diperoleh $p d\left(L_{3,1}\right) \leq 3$. Dari $(i)$ dan $(i i)$, maka $p d\left(L_{3,1}\right)=3$.

Kasus 2. Untuk $m>3$ dan $n>1$.

Akan ditunjukkkan $p d\left(L_{m, n}\right)=m$, Yaitu dengan menunjukkan bahwa,

(i) $p d\left(L_{m, n}\right) \geq m$, Berdasarkan Teorema 2.1 dan $K_{m}$ adalah subgraf dari $L_{m, n}$.

(ii) $p d\left(L_{m, n}\right) \leq m$, Yaitu dengan menunjukkan bahwa himpunan titik $L_{m, n}$ dibagi menjadi $m$ partisi, sedemikian sehingga representasi setiap titik berbeda. Himpunan partisi dari $V\left(L_{m, n}\right)$ dapat didefinisikan sebagai :

$$
\begin{aligned}
S_{i} & =\left\{v_{i}\right\} \text { untuk } 1 \leq i \leq m-1 \\
S_{m} & =\left\{v_{m}, u_{1}, u_{2}, \cdots, u_{i}\right\} \text { untuk } 1 \leq i \leq n
\end{aligned}
$$

Maka diperoleh $p d\left(L_{m, n}\right) \leq m$. Dari $(i)$ dan $(i i)$, maka $p d\left(L_{3,1}\right)=m$. 


\section{Dimensi Partisi Graf Jahangir Diperumum}

Pada bab ini akan dibahas mengenai dimensi partisi dari graf Jahangir diperumum yaitu suatu graf dengan $n m+1$ titik yang memuat sebuah cycle $C_{m n}$ dan satu titik tambahan yang bertetangga dengan $n$ titik dari $C_{m n}$ dengan $m$ jarak yang sama di $C_{m n}$.

Teorema 4.1. Misalkan $J_{m, n}$ adalah graf Jahangir untuk $m \geq 3$ dan $n \geq 3$ maka

$$
p d\left(J_{m, n}\right)= \begin{cases}3 & , \text { untuk } n=3,4,5 \\ \left\lfloor\frac{n}{2}\right\rfloor+1 & , \text { untuk } n \geq 6 .\end{cases}
$$

Bukti. Misalkan $J_{m, n}$ adalah graf Jahangir untuk $m \geq 3$ dan $n \geq 3$ dengan himpunan titik $V\left(J_{m, n}\right)$. Pandang dua kasus berdasarkan nilai $n$.

Kasus 1. Untuk $n=3,4,5$.

Akan ditunjukkkan $p d\left(J_{m, n}\right)=3$, Yaitu dengan menunjukkan bahwa,

(i) $\operatorname{pd}\left(J_{m, n}\right) \geq 3$, berdasarkan Teorema 2.1 diperoleh bahwa $p d\left(J_{m, n}\right) \geq 3$.

(ii) $\operatorname{pd}\left(J_{m, n}\right) \leq 3$, Yaitu dengan menunjukkan bahwa himpunan titik $J_{m, n}$ dibagi menjadi 3 partisi, sedemikian sehingga representasi setiap titik berbeda, maka diperoleh $p d\left(J_{m, n}\right) \leq 3$. Dari $(i)$ dan $(i i)$, maka $p d\left(J_{m, n}\right)=3$.

Kasus 2. Untuk $n \geq 6$.

Akan ditunjukkkan $p d\left(J_{m, n}\right)=\left\lfloor\frac{n}{2}\right\rfloor+1$, Yaitu dengan menunjukkan bahwa,

(i) $\operatorname{pd}\left(J_{m, n}\right) \geq\left\lfloor\frac{n}{2}\right\rfloor+1$, berdasarkan Teorema 2.1 diperoleh bahwa $\operatorname{pd}\left(J_{m, n}\right) \geq$ $\left\lfloor\frac{n}{2}\right\rfloor+1$.

(ii) $\operatorname{pd}\left(J_{m, n}\right) \leq\left\lfloor\frac{n}{2}\right\rfloor+1$, Yaitu dengan menunjukkan bahwa himpunan titik $J_{m, n}$ dibagi menjadi $\left\lfloor\frac{n}{2}\right\rfloor+1$ partisi, sedemikian sehingga representasi setiap titik berbeda, maka diperoleh $p d\left(J_{m, n}\right) \leq\left\lfloor\frac{n}{2}\right\rfloor+1$. Dari $(i)$ dan $(i i)$, maka $p d\left(J_{m, n}\right)=$ $\left\lfloor\frac{n}{2}\right\rfloor+1$.

\section{Kesimpulan}

Pada makalah ini telah dikaji kembali tentang dimensi partisi dari graf lolipop untuk $m \geq 3$ dan $n \geq 1$ dan dimensi partisi dari graf Jahangir diperumum untuk $m \geq 3$ dan $n \geq 3$.

\section{Ucapan Terima Kasih}

Penulis mengucapkan terima kasih kepada bapak Narwen, bapak Admi Nazra, dan ibu Hazmira Yozza yang telah memberikan kritik dan saran pada penulisan makalah ini. 


\section{Daftar Pustaka}

[1] Chartand G, Salehi E, Zhang P., 1998, On the Partition Dimension of A Graph, Congr. Numer. 131: $55-66$

[2] Darmaji, 2011, Dimensi Partisi Graf Multipartit dan Graf Hasil Korona Dua Graf Terhubung, Disertasi, tidak diterbitkan, Jurusan Matematika FMIPA ITB

[3] Mojdeh, D. A., and A. N. Ghameshlou, 2007, Domination in Jahangir Graph $J_{m, n}$, Int. J. Contemp. Math. Sciences 2(24): $193-199$

[4] Tomescu, I., I. Javaid, and Slamin, 2007, On the Partition Dimension and Connected Partition Dimension of Wheels, Ars Combinatoria 84: 311 - 317

[5] Loerdusamy. A, Samuel. S.J dan Mathivanan, 2011. On Pebbling Jahangir Graph. Gen. Math. Notes, 5(2) : $42-49$

[6] Weisstein, E. W., 2003, CRC Concise Encyclopedia oh Mathematics CD-ROM, $2^{e d}$, CRC Press, Boca Raton

[7] Chartand G, Salehi E, Zhang P., 2000, The Partition Dimension of A Graph. Aequation Math. 55: 45 - 54 